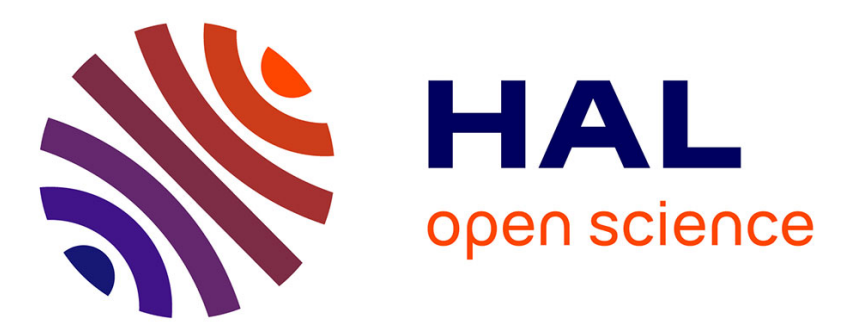

\title{
Shortening of gestational length among native-born and immigrants in Spain (1997-2008)
}

\author{
Adela Castelló, Isabel Río, María Sandín-Vázquez, Francisco Bolúmar
}

\section{To cite this version:}

Adela Castelló, Isabel Río, María Sandín-Vázquez, Francisco Bolúmar. Shortening of gestational length among native-born and immigrants in Spain (1997-2008). European Journal of Epidemiology, 2011, 26 (7), pp.563-570. 10.1007/s10654-011-9591-4 . hal-00708544

\section{HAL Id: hal-00708544 https://hal.science/hal-00708544}

Submitted on 15 Jun 2012

HAL is a multi-disciplinary open access archive for the deposit and dissemination of scientific research documents, whether they are published or not. The documents may come from teaching and research institutions in France or abroad, or from public or private research centers.
L'archive ouverte pluridisciplinaire HAL, est destinée au dépôt et à la diffusion de documents scientifiques de niveau recherche, publiés ou non, émanant des établissements d'enseignement et de recherche français ou étrangers, des laboratoires publics ou privés. 
TITLE: Shortening of gestational length among native-born and immigrants in Spain (1997-2008).

Authors: Adela Catelló-Pastor ${ }^{\mathrm{a}}$ PhD, Isabel Río ${ }^{\mathrm{b}}$ PhD, María Sandín-Vázquez PhD, Francisco Bolúmar ${ }^{\mathrm{a}, \mathrm{b}}$ MD, MPH, PhD.

${ }^{a}$ Department of Public Health Sciences, Faculty of Medicine, University of Alcalá, Madrid, Spain.

${ }^{\mathrm{b}}$ Division of Environmental and Reproductive Epidemiology, Spanish Network for Research in Epidemiology and Public Health (CIBERESP), Spain.

\section{CORRESPONDING AUTHOR}

Francisco Bolúmar

Department of Public Health Sciences

Faculty of Medicine

University of Alcalá

Madrid (Spain)

Phone: +34 918852556

Fax: 34918854874

e-mail: francisco.bolumar@uah.es 


\begin{abstract}
During the last decade there have been significant socio-demographic changes in Spain with potential impact on gestational length. The aim of the study was to describe the evolution of gestational age during 1997-2008, separately for native-born and immigrant population, in order to assess their contribution to the overall pattern of gestational length.

A cross-sectional study of 5,018,229 singleton births born between 1997 and 2008 was carried out. The annual mean of gestational age was calculated and compared by means of ANOVA test, globally and also separately for natives and immigrants. Proportions of deliveries by gestational age and maternal characteristics were calculated in 4 periods and compared by means of Chi-square tests. Crude and adjusted multinomial logistic regression models were fitted separately for native-born and immigrant women.

Our results show that in the last 12 years a progressive shortening in the mean gestational age has taken place in Spain. While the overall decrease of gestational length along the period was 1.5 days, closer to that in Spanish women (1.1 days), it was 2.3 days among immigrants. In both groups this shortening was mainly due to an increase in the proportion of 37-39 weeks deliveries at the expense of a substantial decrease in those with 40 weeks. These trends remained after controlling for known confounding variables such as maternal age, parity and occupation.

Further analysis of its causes and public health implications are recommended.
\end{abstract}

Keywords: Duration of pregnancy; Gestational age; Immigrants 


\section{Introduction}

Length of gestation is a key reproductive indicator because the survival and health status of the newborns depend largely on their maturity at birth. In humans, fetal development is considered normal in duration when birth occurs between the $37^{\text {th }}$ and the $41^{\text {st }}$ gestational week. Longer, and above all, shorter gestational times are associated to higher health risk and lower probability of survival. A wide range of factors can harmfully influence the duration of development in uterus. In industrialized countries, the greater access to contraceptive methods and the massive incorporation of women into the labor market have contributed significantly to the reduction of birth rates and to a later age of motherhood. In this regard, it is known that primiparae and women with first motherhood at $>30$ years have shorter pregnancies than multiparae and younger women, respectively ${ }^{1-4}$. Emotional stress and anxiety, high workload and exposure to toxics are variables with a known negative impact on the duration of pregnancies ${ }^{5-10}$. At the clinical setting, programs to reduce post-term pregnancies, better survival of increasingly premature births, increase of fertility treatments and obstetrical procedures such as elective caesarean section or elective induced labor are all factors that contribute to reduce the average duration of gestational age at birth in a population ${ }^{1,14-16}$. The coexistence of many of these factors in current industrialized societies could be the explanation for the shortening of the gestational length identified in some recent studies ${ }^{17-20}$.

In Spain, there have been significant socio-demographic changes during the last decade with impact on reproductive outcomes. On the one hand, the process of incorporating women into the labor market has consolidated. The main consequence of this process has been a delay of the first maternity, increasing the number of primiparae older mothers $^{21}$ and the number of women having to resort to infertility treatments ${ }^{22}$. 
On the other hand, over the last decade there has been a massive arrival of immigrants to the country ${ }^{23}$. Immigrants are a population largely in reproductive age and an important increase in the number of births from immigrant mothers has taken place ${ }^{24}$. Several studies have found significant differences in duration of gestational length amongst different ethnic groups ${ }^{25-27}$, and the higher proportion of children with shorter gestational age born to immigrant mothers has been proposed as one possible explanation for changes in the gestational length in European countries ${ }^{28,29}$. Therefore, the aim of this study was to describe the evolution of the duration of gestational age during the period 1997-2008 in Spain, separately for native-born and immigrant population in order to assess their contribution to the overall pattern of gestational length.

\section{Methods}

Registration of newborns is mandatory for all births occurring in Spain, regardless of the mother's nationality. All single births during the period 1997-2008 were selected from the Spanish Vital Statistics Registry. Data on gestational age at birth (weeks), parity, age, occupation and on country of origin of the mother were available.

According to this information mothers were grouped by parity (primiparae, one previous delivery, two or more previous deliveries) and 3 categories of age $(<20,20-34$ and 35 or more years), 4 types of work (managerial or clerical, services or manufacturing, farm work or related and no job) and as Spanish, economic immigrants (coming mainly from Latin America [Ecuador, Colombia, Bolivia, Peru], Eastern Europe [Romania, Bulgaria], Maghreb [Morocco and Algeria], and Sub-Saharian Africa [Senegal and Gambia]) or non economic immigrants (coming from developed countries). 
Births from mothers coming from developed countries showed a similar reduction in gestational weeks (1.12 days) than the Spanish for the whole period. Therefore, the analyses were carried out considering two groups: Spanish and Immigrant (considered as those coming from countries economically disadvantaged)

For both natives and immigrants, we compared the evolution of the mean gestational age by year and the statistical significance of the differences was assessed using ANOVA test. To assess differences in the distribution of the gestational age along the study period within each of the two population groups, we classified deliveries in 4 periods (1997-1999, 2000-2002, 2003-2005 and 2006-2008) and in 4 categories of gestational age: Very Preterm Birth (VPB, $\leq 32$ weeks), Moderate Preterm Birth (MPB, 33-36 weeks), At Term birth (37 to 41 weeks, also subdivided in 3 subcategories 37-39, 40 and 41 weeks) and Post-term birth ( $\geq 42$ weeks). Proportions of births by category of gestational age across the 4 periods were calculated and compared by means of chisquare test as well as proportion of births by parity and categories of maternal age, origin and type of work. Gestational age was also graphically represented.

To quantify the risk of having very preterm, moderate preterm and post-term deliveries along the 4 periods considered and the influence of variables with known impact on the duration of gestation we fitted crude and adjusted multinomial logistic regression models (with 37-41 weeks as the baseline category) separately for natives and immigrants. Additionally, separately for each group, we explored the evolution of the odds of delivering at term babies with 37-39 weeks by means of crude and adjusted binary logistic regression models (with 40 weeks as the reference category). In all crude and adjusted models Odds Ratios (OR) and their 95\% Confidence Intervals (95\%C I) were obtained. 


\section{Results}

5,018,229 singleton births were registered between 1997 and 2008 in Spain, 88\% of them corresponding to Spanish women and $12 \%$ to immigrants $(10.63 \%$ economic immigrants and $1.37 \%$ non economic immigrants). Data on parity, age, area of origin and occupation of the mother were complete, but gestational age data were missing for $13.36 \%$ of newborns from Spanish mothers and for $20.69 \%$ of newborns from immigrants.

The evolution of the mean gestational age over time for all births (native born and immigrants jointly) showed a gradual decrease, going from 39.28 weeks in 1997 to 39.07 in 2008, a mean decrease of 1.47 days. As Figure 1 shows, among native-born women the mean gestational age decreased from 39.27 weeks in 1997 to 39.09 in 2008 , a mean decrease of 1.26 days. Economic Immigrant women showed a more noticeable gestational shortening over time than Spanish, going from 39.32 weeks in 1997 to 38.99 in 2008, a mean decrease of 2.31 days (1.79 days for Latin-American, 3.24 for East European, 2.02 for North-African, 2.24 for Sub-Saharan and 3.03 for Asian). Differences in mean gestational age along the years were statistically significant in both groups.

The proportion of deliveries by gestational age along the 4 periods considered are summarised in Table 1 and represented in Figure 2. The number of deliveries from Spanish mothers increased slightly from 1997-1999 to 2006-2008 in 127,663 births. During this time, the decrease in the prevalence of preterm births was marginal. The shortening of the mean gestational age is due to a striking decrease in the proportion of at term births with 40 weeks in favor of an increase of births with 37-39 weeks. A decrease of post-term deliveries over time also contributed to the shortening of gestational age in Spanish newborns. Among immigrants, the number of deliveries has 
experienced a marked 7-fold increase from first to last period. In contrast to Spanish women, shortening of the mean gestational age observed in immigrant women is partly consequence of a clear increase of preterm births over time, mainly attributable to moderate preterm but also to very preterm deliveries. However, the main reason for gestational shortening in immigrants was a more marked decrease than in Spanish in the proportion of 40 weeks deliveries in favor of births with 37-39 weeks. This more pronounced shift to the left in the length of at term gestation among immigrants is seen in Figure 2. A higher decrease of post-term deliveries was also evident among immigrants along the period.

Table 2 shows the proportion of deliveries according to maternal characteristics. The proportion of primiparae mothers among Spanish has slightly increased over time. More noticeable was the increase in the proportion of older mothers practically doubling the percentage of women giving birth after 35 from 1997-1999 to 2006-2008. Unlike Spanish mothers, the proportion of primiparae in immigrants decreased and no remarkable changes occurred in the proportion of deliveries from $\geq 35$ years mothers. Both, Spanish and immigrants showed a reduction in the proportion of deliveries from non working mothers, parallel to an increase of deliveries from mothers working in services and manufacturing and in managerial and clerical jobs but also in farm work or related in immigrants.

Analyses showing the evolution of the risk of gestational shortening in preterm and post-term deliveries are shown in table 3 . The adjusted risk of very preterm delivery for Spanish mothers was an 11\% bigger in 2006-2008 than in 1997-1999 while the adjusted risk of moderate preterm birth seems to have decreased slightly along the period (5\% smaller). More noticeable was the progressive reduction of the risk of post-term delivery, a 17\%, 24\% and 34\% lower in 2000-2002, 2003-2005 and 2006-2008, 
respectively, than in 1997-1999. For immigrant women, the adjusted risk of very preterm delivery was $34 \%$ higher in 2006-2008 than in 1997-1999, clearly higher than for Spanish women. Moreover, unlike Spanish, the risk of moderate preterm delivery increased for immigrants being $18 \%$ higher in the last period. Analysis of post-term showed, as for Spanish, a progressive reduction in the risk over time, 19\%, 20\% and 42\% lower in 2000-2002, 2003-2005 and 2006-2008, respectively, than in 1997-1999.

Finally, the evolution of the odds of gestational shortening among at term deliveries is shown in table 4. A gradual increase over time in the adjusted risk of being born at 37 39 weeks at the expense of deliveries with 40 weeks occurred both in Spanish and immigrants, but more pronounced in the latter group.

\section{Discussion}

Our results show that in the last 12 years a progressive shortening in the mean gestational age of live births has taken place in Spain. While the overall decrease of gestational length along the period was 1.47 days, closer to that in Spanish women $(1.26$ days), it was 2.31 days among immigrants (3.24 days in Eastern European). In both Spanish and immigrants this shortening was mainly due to an increase in the proportion of 37-39 weeks deliveries at the expense of a substantial decrease in those with 40 weeks, but also to a reduction in the prevalence of post-term deliveries. However, among immigrant women, an increase of very and moderate preterm deliveries over time has also contributed to the gestational shortening. Those effects remained after controlling for known confounding variables such as maternal age, parity and occupation.

Trends of gestational shortening have been reported in other countries ${ }^{17-20}$. A study carried out in Australia ${ }^{17}$ including births from 1990 to 1996 showed a decline in 40 and 
$\geq 42$ weeks' births and a concomitant increase of term births with 38-39 weeks of gestation. Although the pattern was similar to that found in our study, theirs was confined to $\geq 37$ weeks' deliveries and carried out only in the region of New South Wales. In the United States, the analysis of births in 1992, 1997 and 2002 from mothers of different racial/ethnic groups ${ }^{18}$ showed a shift to the left in gestational age, from 40 weeks as the most frequent length of gestation in 1992 to 39 weeks in 2002. This shift was consequence, again, of a decline in the proportion of post-term and 40 weeks' births, but also in those at 41 weeks. A more recent study including at term births from 1990 to 2005 in the United States ${ }^{20}$ confirms a decrease of more than 2 days in the mean length of gestation as a consequence of the decline of births with 40-41 weeks. In the only, to our knowledge, European study which has analyzed the evolution of gestational age, a shift toward shorter times of gestation was identified among Italian at term births ( $\geq 37$ weeks) born between 1990 and $1998^{19}$. Along this period the mean gestational age was reduced by 1.33 days, quite similar to the reduction observed in Spain.

Our study was nationwide, looking at term births but also preterm and post-term. The period considered was recent and longer than in most previous studies.

One significant problem of the study is the large number of cases with missing information on gestational age, especially for deliveries from immigrant mothers. Although in Spain there is universal access to health care, even for undocumented immigrants, we can not rule out the possibility that cases with no data for gestational age might represent births of immigrant women with limited access to health care services. Limited access to health care has been related with worse reproductive results (prematurity, low birth weight) in immigrant populations ${ }^{30-33}$. Even under this hypothetical scenario, it is doubtful that missing data on gestational age explains the shortening of gestational age identified in this study, although the estimated difference 
between Spanish and immigrants could be higher. In order to check this hypothesis and considering the correlation between gestational age and birth weight, we have checked the information about this last variable among cases with missing gestational age. Information on newborn's weight was missing for only $4.96 \%$ of cases and we checked that $95.82 \%$ (95.7\% for Spanish and $96.22 \%$ for immigrants) of births with missing value for gestational age were babies with weight over 2500grs (mean birth weight $3,246.47$ and 3,316.86 respectively). Therefore it is unlikely that infants who do not have data for gestational age are the most premature.

On the other hand, the possibility of gestational shortening as an artifact stemming from a more accurate reporting of the duration of pregnancies over time needs to be considered. The Spanish Vital Statistics Registry registers information on gestational age provided by parents or relatives at the time of birth registration. A change over time in the accuracy of reporting seems unlikely. The fluctuation in the degree of completeness of this variable throughout the period analyzed does not explain consistently the trends identified in the study.

A change along the period in the method used for gestational age determination might have an impact on the estimated gestational age. In fact, several studies have consistently shown that, compared to the last menstrual period dating, early ultrasound dating results in a shift to the left in the gestational age distribution ${ }^{34,35}$. However, no changes in the method for determination of the gestational age have occurred in Spain during the period considered.

Data shows that the mean gestational age for immigrants exceeds the Spanish until 2005, but dropped thereafter. Immigration in Spain is a recent phenomenon. Latin American and North-African women have been the largest immigrant population groups during the last decade, but in recent years there has been a very rapid increase in the 
affluence of women from Eastern Europe and Sub-Saharan Africa with a notable increase of births to mothers from these geographical areas. Similar or better reproductive outcomes than for native women have been reported for immigrant women from Latin-America or North-African in different contexts ${ }^{37-39}$, although a worsening in their reproductive indicators parallel to the increased time of residence in the host country has been reported ${ }^{40-42}$. In Spain, a recent study shows that more recent immigrant women from Eastern-Europe and Sub-Sahara have a much higher risk of prematurity than other immigrant groups or Spanish-born women ${ }^{43}$ and our data shows that those two immigrant groups have experienced the greatest decrease in gestational age. Collectively, all this evidence could explain the increased difference between Spanish and immigrants in the decline of the mean gestational age in most recent years. According to these considerations, the trend identified in our study seems to reflect a real change. Underlying causes for a true shortening in the mean length of gestation might be concomitant changes in maternal characteristics ${ }^{1-4}$ and/or in the obstetric practice $^{14-16}$ along the period studied. Our results show an increasing proportion of primiparae over time only among Spanish women. Given the positive association between primiparity and the risk of reduced length of gestation ${ }^{1-4}$, this difference between Spanish and immigrant women might predict a more pronounced shortening among Spanish. However, adjusted analyses showed a major risk of gestational shortening for immigrants, parity not being an explanatory variable of shortening neither in the Spanish nor in the immigrant group. Deliveries from women $\geq 35$ years increased over time only among natives and adjusted analyses of risk suggest that gestational shortening occurs independently of mother's age in both population groups. Regarding the assessment of the impact of changes in obstetrical procedures throughout the period, our study have a limitation because the Spanish Vital Statistics Registry do 
not provide information about the type of delivery (spontaneous or induced) and only since recently (2007) about the mode of delivery (vaginal or caesarean section). The increase in induced deliveries and caesarean sections along the period analyzed is well documented in Spain $^{36}$, and therefore their possible influence on our results cannot be ruled out. However, the studies previously mentioned show that shortening of gestational length is quite independent of type and mode of delivery and of maternal age. The study carried out in New South Wales ${ }^{17}$ found that the shift to earlier gestational ages also occurred among women less than 35 years and among births with spontaneous onset. In one of the studies performed in the USA ${ }^{18}$ the shift to the left in the distribution of gestations occurred among all three categories of delivery: spontaneous, induced/caesarean and those with premature rupture of membranes. The more specific analysis of the evolution of deliveries ${ }^{20}$ conducted in the other USA study also confirmed that neither statistical adjustment by maternal and neonatal characteristics or by obstetric practices nor restriction of the sample to a homogeneous low-risk subgroup -none of whom were induced or delivered by caesarean sectionattenuated observed declines in gestational duration of term births. Finally, the study performed in Italy ${ }^{19}$ showed that the shortening experienced in pregnancies from mothers $<30$ years was more relevant than that occurred in pregnancies among older mothers independently of the educational level.

Another factors with known negative impact on the duration of pregnancy but not recorded in birth records are the nutritional status of the women, the exposition to toxics, the emotional stress and anxiety or the presence of specific medical conditions ${ }^{5-}$ 10. We cannot rule out temporal changes in some of these factors that might contribute to the identified decline in the gestational length. In this regard, detailed studies would be needed to explore their influence on delivery at the population level. There is also a 
positive association among infertility treatments and reduced length of gestation ${ }^{14,15}$. In Spain, an increase of infertility treatments over the period analyzed has occurred ${ }^{22}$, but we consider that it does not explain neither shortening among at term pregnancies or the higher gestational shortening experienced by immigrant women.

The mean gestational age was quite similar between native-born and immigrants for the first three periods considered and differed markedly for the last period. This difference was due not only to a significant increase in preterm births but also in early at term births. Thus, given that the number of births from immigrant mothers increased notably in this last period, the differentiated contribution of immigrants to the overall gestational shortening was bounded to the period 2006-8.

Neither the underlying reasons for the gestational age shortening nor the consequences of such a decline are definitely established. Since the duration of gestation is a predictor of short and long-term disease risk among preterm but also among term newborns, it seems necessary to carry out further research to monitor this trends, with particular attention to differences among population groups.

\section{Acknowledgments}

Spanish Ministry of Science and Innovation (SEJ 2005/07679);

CIBER of Epidemiology and Public Health (Ciberesp, Spain). 


\section{References}

1. Bergsjø P, Denman DW 3rd, Hoffman HJ, Meirik O. Duration of human singleton pregnancy. A population-based study.Acta Obstet Gynecol Scand. 1990;69(3):197-207.

2. Delpisheh A, Brabin L, Attia E, Brabin BJ. Pregnancy late in life: a hospitalbased study of birth outcomes. J Womens Health (Larchmt). 2008;17(6):965-70.

3. St-Laurent J, De Wals P, Moutquin JM, Niyonsenga T, Noiseux M, Czernis L. Biopsychosocial determinants of pregnancy length and fetal growth. Paediatr Perinat Epidemiol. 2008;22(3):240-8.

4. Petridou E, Trichopoulos D, Tong D, Revinthi K, Tsitsika A, Papathoma E, Aravantinos D. Modulators of length of gestation. A study in Greece. Eur $\mathbf{J}$ Public Health. 1996;6:159-65.

5. Hosseini SM, Biglan MW, Larkby C, Brooks MM, Gorin MB, Day NL. Trait anxiety in pregnant women predicts offspring birth outcomes. Paediatr Perinat Epidemiol. 2009;23(6):557-66.

6. Tegethoff M, Greene N, Olsen J, Meyer AH, Meinlschmidt G. Maternal Psychosocial Adversity During Pregnancy Is Associated With Length of Gestation and Offspring Size at Birth: Evidence From a Population-Based Cohort Study. Psychosom Med. 2010;72(4):419-26.

7. Mamelle N, Laumon B, Lazar P. Prematurity and occupational activity during pregnancy. Am J Epidemiol 1984;119:309-22.

8. Saurel-Cubizolles MJ, Zeitlin J, Lelong N, Papiernik E, Di Renzo GC, Bréart G; Europop Group. Employment, working conditions, and preterm birth: results 
from the Europop case-control survey. J Epidemiol Community Health. 2004;58(5):395-401.

9. Guendelman S, Pearl M, Graham S, Hubbard A, Hosang N, Kharrazi M. Maternity leave in the ninth month of pregnancy and birth outcomes among working women. Womens Health Issues. 2009;19(1):30-7.

10. Stillerman KP, Mattison DR, Giudice LC, Woodruff TJ. Environmental exposures and adverse pregnancy outcomes: a review of the science. Reprod Sci. 2008;15(7):631-50. Review.

11. Tuck SM, Cardozo LD, Studd JW, Gibb DM, Cooper DJ. Obstetric characteristics in different racial groups.Br J Obstet Gynaecol 1983;90:892-7.

12. McFadyen IR, Campbell-Brown MC, Abraham R, North WR, Haines AP. Factors affecting birthweights in Hindus, Moslems and Europeans. Br J Obstet Gynaecol 1984; 91:968-72.

13. Patel RR, Steer P, Doyle P, Little M, Elliott P. Does gestation vary by ethnic group? A London-based study of over 122,000 pregnancies with spontaneous onset of labour. Int J Epidemiol 2004; 33:107-13. Comment in: Int J Epidemiol 2004; 33:114-5.

14. Allen VM, Wilson RD, Cheung A; Genetics Committee of the Society of Obstetricians and Gynaecologists of Canada (SOGC); Reproductive Endocrinology Infertility Committee of the Society of Obstetricians and Gynaecologists of Canada (SOGC). [Pregnancy outcomes after assisted reproductive technology]. J Obstet Gynaecol Can. 2006;28(3):220-50.

15. Welmerink DB, Voigt LF, Daling JR, Mueller BA. Infertility treatment use in relation to selected adverse birth outcomes. Fertil Steril. doi:10.1016/j.fertnstert.2010.03.005 
16. Oshiro BT, Henry E, Wilson J, Branch DW, Varner MW; Women and Newborn Clinical Integration Program. Decreasing elective deliveries before 39 weeks of gestation in an integrated health care system. Obstet Gynecol. 2009;113(4):80411.

17. Roberts CL, Taylor L, Henderson-Smart D. Trends in births at and beyond term: evidence of a change? Br J Obstet Gynaecol. 1999;106(9):937-42.

18. Davidoff MJ, Dias T, Damus K, Russell R, Bettegowda VR, Dolan S, Schwarz RH, Green NS, Petrini J. Changes in the gestational age distribution among U.S. singleton births: impact on rates of late preterm birth, 1992 to 2002. Semin Perinatol. 2006;30(1):8-15.

19. Astolfi P, De Pasquale A, Zonta LA. Gestational age shortening in single births at term. Italy 1990-1998. Eur J Epidemiol. 2007;22(4):263-5.

20. Donahue SM, Kleinman KP, Gillman MW, Oken E. Trends in birth weight and gestational length among singleton term births in the United States: 1990-2005. Obstet Gynecol. 2010;115(2 Pt 1):357-64.

21. Bosch X. Investigating the reasons for Spain's falling birth rate. Lancet. 1998;12;352(9131):887.

22. Matorras R, Expósito A, Carreras M. Fertility policy in Spain. Pharmaceuticals Policy and Law.2007;9:229-33. http://iospress.metapress.com/content/11l3dg5j7vx45vny/fulltext.pdf Accessed 02 July 2010.

23. Spanish National Statistics Register. Population in 2009 by country of birth. http://www.ine.es/jaxi/tabla.do?path=/t20/e245/p04/provi/10/\&file=00000011.P X\&type $=$ pcaxis \&L=0 Accessed 01 July 2010. 
24. Spanish National Statistics Register. Births by mother's nationality in 2009. http://www.ine.es/jaxi/tabla.do?path=/t20/e301/nacim/a2008/10/\&file=05005.px \&type $=$ pcaxis \&L=0 Accessed 01 July 2010.

25. Papiemik E, Alexander GR, Paneth N. Racial differences in pregnancy duration and its implications for perinatal care. Med Hypotheses. 1990;33:181-86.

26. Wilcox M, Gardosi J, Mongelli M, Ray C, Johnson I. Birthweight from pregnancies dated by ultrasonography in a multicultural British population. BMJ 1993;307:588-91.

27. Patel RR, Steer P, Doyle P, Little MP, Elliott P. Does gestation vary by ethnic group? A London-based study of over 122,000 pregnancies with spontaneous onset of labour. Int J Epidemiol. 2004;33(1):107-13.

28. Nielsen J, ed. Births and infant mortality in the Nordic countries.Copenhagen: Nordic Medico-Statistical Committee (NOMESCO), 1993:39.

29. Stoltenberg C, Magnus P. Children with low birth weight and low gestational age in Oslo, Norway: immigration is not the cause of increasing proportions. $\mathbf{J}$ Epidemiol Community Health. 1995;49(6):588-93.

30. Malin, M. and M. Gissler (2009). "Maternal care and birth outcomes among ethnic minority women in Finland." BMC Public Health 9: 84

31. Manzanares Galan, S., M. F. López Gallego, et al. (2008). "Results of poor prenatal care in the immigrant population." Progresos de Obstetricia y Ginecología 51(4): 9

32. Puig Sola, C., A. Zarzoso Palomero, et al. (2008). "[Hospital admission in newborns according to ethnicity and parents' country of origin in an urban area of Barcelona [Spain]]." Gac Sanit 22(6): 555-64 
33. Tierney-Gumaer, R. and E. Reifsnider (2008). "Risk factors for low birth weight infants of Hispanic, African American, and White women in Bexar County, Texas." Public Health Nurs 25(5): 390-400

34. Yang H, Kramer MS, Platt RW, Blondel B, Bréart G, Morin I, Wilkins R, Usher R. How does early ultrasound scan estimation of gestational age lead to higher rates of preterm birth? Am J Obstet Gynecol. 2002;186(3):433-7.

35. Ananth CV. Menstrual versus clinical estimate of gestational age dating in the United States: temporal trends and variability in indices of perinatal outcomes. Paediatr Perinat Epidemiol. 2007;21 Suppl 2:22-30.

36. Indicadores de actividad hospitalaria en España. (2000-2005). http://www.msc.es/estadEstudios/estadisticas/docs/serie_escri_00_05_es.pdf Accessed 30 July 2010.

37. Guendelman S, Buekens P, Blondel B, Kaminski M, Notzon FC, MasuyStroobant G. Birth outcomes of immigrant women in the United States, France, and Belgium. Matern Child Health J. 1999 Dec;3(4):177-87.

38. Vahratian A, Buekens P, Delvaux T, Boutsen M, Wang Y, Kupper LL. Birthweight differences among infants of North African immigrants and Belgians in Belgium. Eur J Public Health. 2004 Dec;14(4):381-3.

39. Buekens P, Masuy-Stroobant G, Delvaux T.High birthweights among infants of north African immigrants in Belgium.Am J Public Health. 1998 May;88(5):80811.

40. Callister LC, Birkhead A.Acculturation and perinatal outcomes in Mexican immigrant childbearing women: an integrative review.J Perinat Neonatal Nurs. 2002 Dec;16(3):22-38. Review. 
41. Page RL.Positive pregnancy outcomes in Mexican immigrants: what can we learn? J Obstet Gynecol Neonatal Nurs. 2004 Nov-Dec;33(6):783-90. Review.

42. Urquia ML, Frank JW, Moineddin R, Glazier RH. Immigrants' duration of residence and adverse birth outcomes: a population-based study.BJOG. 2010 Apr;117(5):591-601.

43. Río I, Castelló A, Jané M, Prats R, Barona C, Más R, Rebagliato M, Zurriaga O, Bolúmar F. [Reproductive and perinatal health indicators in immigrant and Spanish-born women in Catalonia and Valencia (2005-2006)]. Gac Sanit. 2010 Mar-Apr;24(2):123-7. Epub 2009 Dec 14. Spanish.

\section{FIGURES}

Figure 1. Annual evolution of the mean gestational age in deliveries from Spanish and immigrant women (1997-2008)

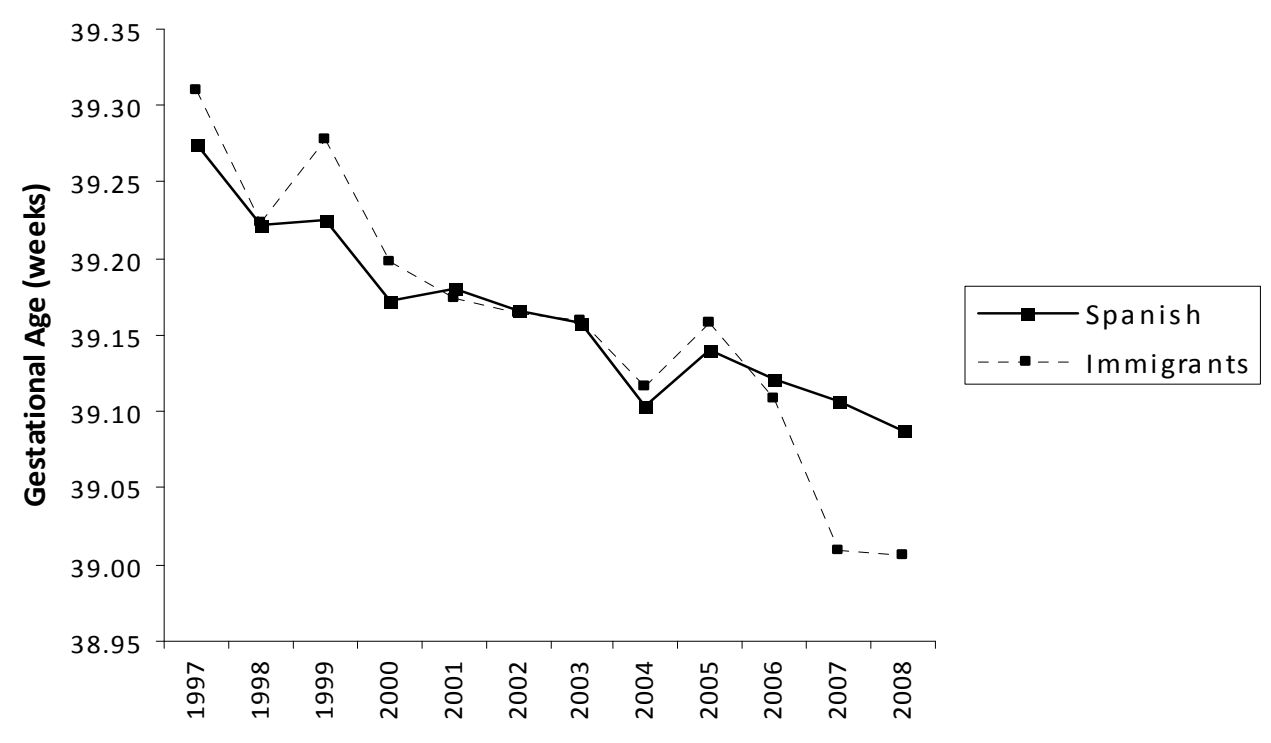

Figure 2. Evolution of the proportion of births by gestational age among Spanish and immigrant women 

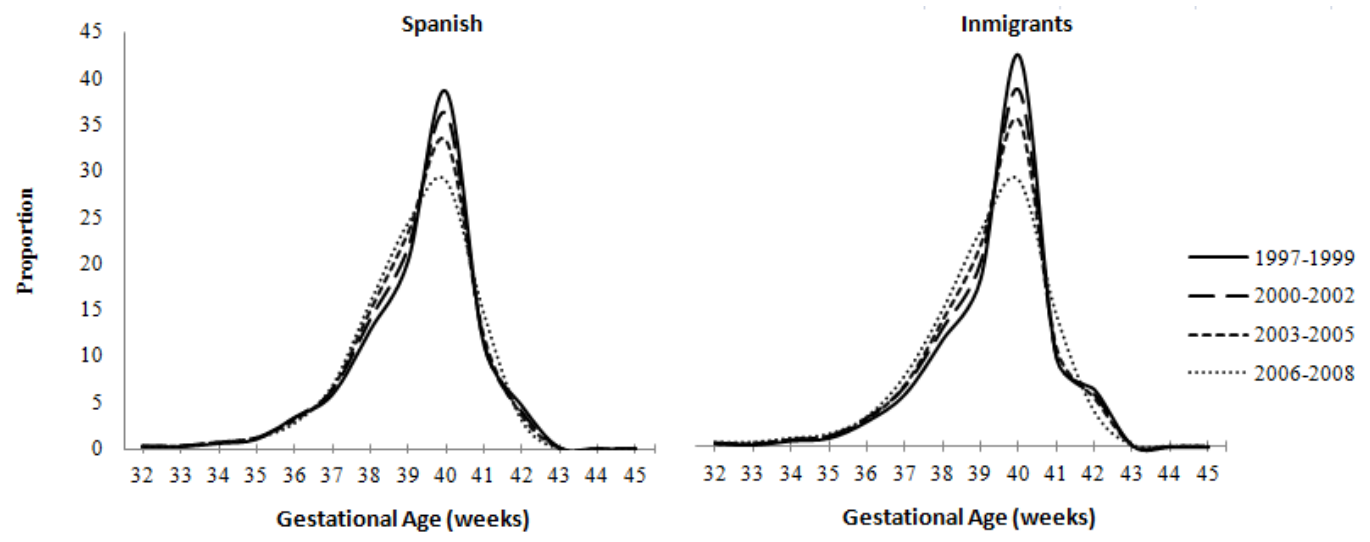


\section{TABLES}

Table 1. Proportion of deliveries by gestational age (GA) in 4 periods among Spanish and immigrant women

\begin{tabular}{|c|c|c|c|c|c|c|c|c|}
\hline & \multicolumn{4}{|c|}{ SPANISH n (\%) } & \multicolumn{4}{|c|}{ IMMIGRANTS n(\%) } \\
\hline & $1997-1999^{a}$ & $2000-2002^{a}$ & $2003-2005^{a}$ & $2006-2008^{a}$ & $1997-1999^{a}$ & $2000-2002^{\mathrm{a}}$ & $2003-2005^{a}$ & $2006-2008^{a}$ \\
\hline BIRTHS & 1036431 & 1082448 & 1131506 & 1164094 & 34293 & 84966 & 164167 & 249801 \\
\hline BIRTHS WITH GA & $885037(85.39 \%)$ & $949150(87.69 \%)$ & $1010997(89.35 \%)$ & $979735(84.16 \%)$ & $27140(79.14 \%)$ & $69979(82.36 \%)$ & $137835(83.96 \%)$ & $183924(73.63 \%)$ \\
\hline PRETERM $^{\mathrm{b}}$ & $55747(6.3 \%)$ & $59776(6.3 \%)$ & $62460(6.18 \%)$ & $59551(6.08 \%)$ & $1601(5.9 \%)$ & $4521(6.46 \%)$ & $8811(6.39 \%)$ & $13321(7.24 \%)$ \\
\hline VPT $(\leq 32)^{\mathbf{b}}$ & $7354(0.83 \%)$ & $7968(0.84 \%)$ & $8420(0.83 \%)$ & $8971(0.92 \%)$ & $323(1.19 \%)$ & $822(1.17 \%)$ & $1585(1.15 \%)$ & $2668(1.45 \%)$ \\
\hline MPT $(33-36)^{b}$ & $48393(5.47 \%)$ & $51808(5.46 \%)$ & $54040(5.35 \%)$ & $50580(5.16 \%)$ & $1278(4.71 \%)$ & $3699(5.29 \%)$ & $7226(5.24 \%)$ & $10653(5.79 \%)$ \\
\hline AT TERM $^{\mathrm{b}}$ & $786154(88.83 \%)$ & $850511(89.61 \%)$ & $911329(90.14 \%)$ & $889212(90.76 \%)$ & $23793(87.67 \%)$ & $61420(87.77 \%)$ & $121630(88.24 \%)$ & $163590(88.94 \%)$ \\
\hline $37-39^{b}$ & $345299(39.02 \%)$ & $398883(42.03 \%)$ & $452426(44.75 \%)$ & $461434(47.1 \%)$ & $9693(35.71 \%)$ & $27609(39.45 \%)$ & $58370(42.35 \%)$ & $84545(45.97 \%)$ \\
\hline $40^{b}$ & $341166(38.55 \%)$ & $343780(36.22 \%)$ & $336506(33.28 \%)$ & $284358(29.02 \%)$ & $11511(42.41 \%)$ & $27066(38.68 \%)$ & $48708(35.34 \%)$ & $53156(28.9 \%)$ \\
\hline $41^{b}$ & $99689(11.26 \%)$ & $107848(11.36 \%)$ & $122397(12.11 \%)$ & $143420(14.64 \%)$ & $2589(9.54 \%)$ & $6745(9.64 \%)$ & $14552(10.56 \%)$ & $25889(14.08 \%)$ \\
\hline POST-TERM $^{\mathrm{b}}$ & $43136(4.87 \%)$ & $38863(4.09 \%)$ & $37208(3.68 \%)$ & $30972(3.16 \%)$ & $1746(6.43 \%)$ & $4038(5.77 \%)$ & $7394(5.36 \%)$ & $7013(3.81 \%)$ \\
\hline
\end{tabular}

${ }^{\text {a }}$ Figures do not add up because of missing values.

${ }^{\mathrm{b}}$ Comparisons of the percentages along the 4 periods in each GA category were statistically significant $(\mathrm{p}$-value $<0.001)$ 
Table 2. Proportion of deliveries by maternal characteristics in 4 periods among Spanish and immigrant women.

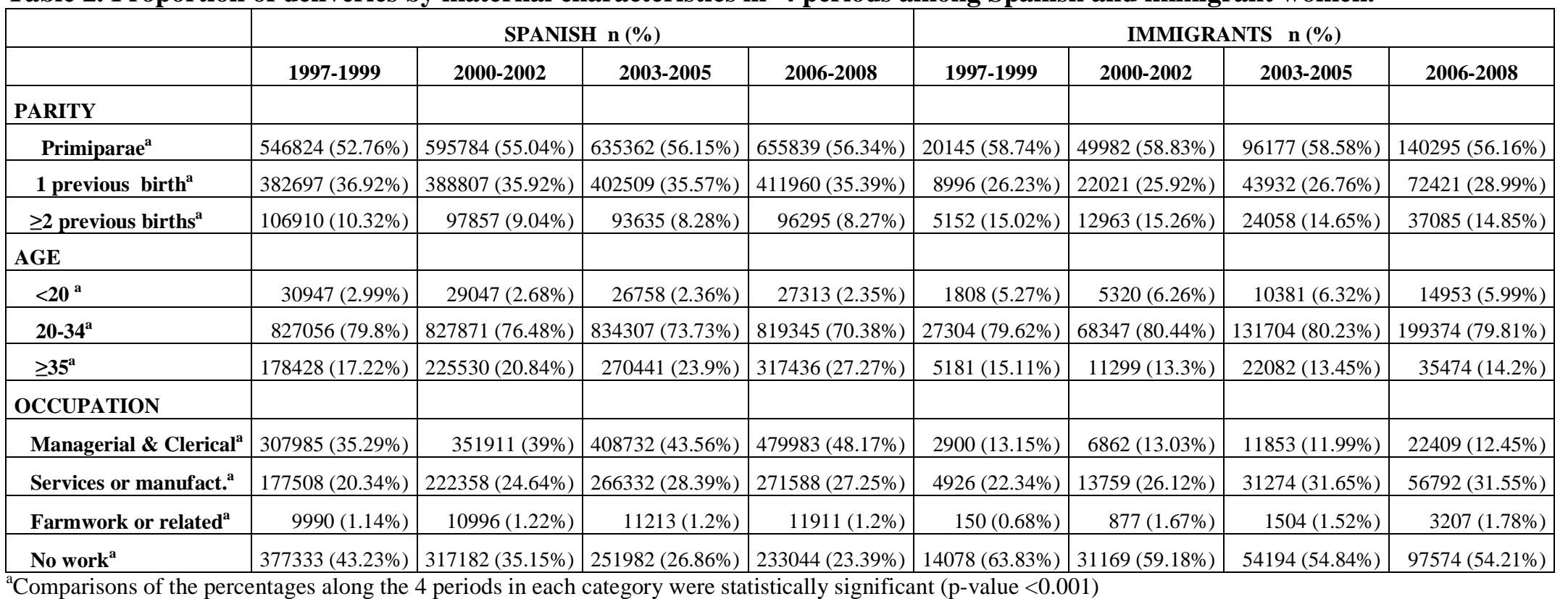


Table 3. Evolution of the risk of Very preterm (VPB), moderate preterm (MPB) and post-term birth.

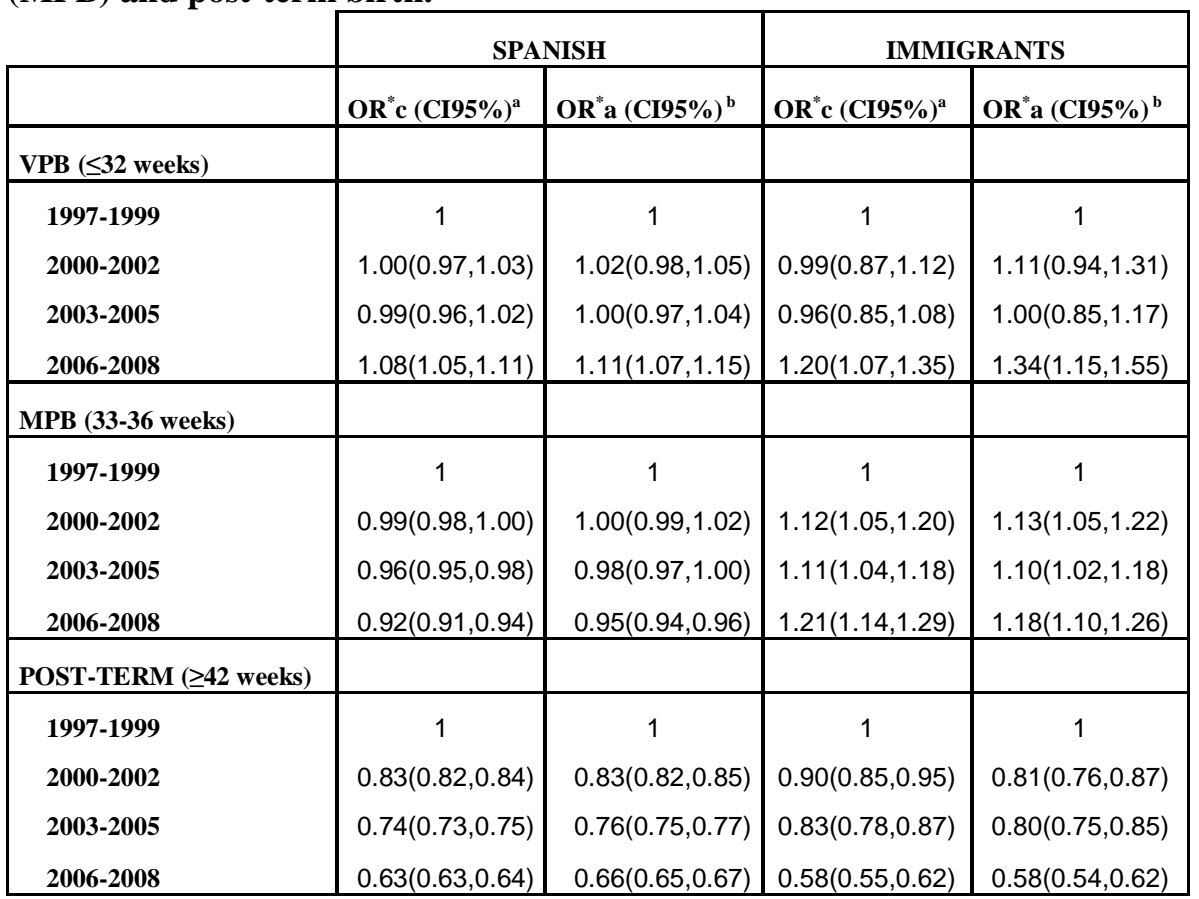

${ }^{\mathrm{a}} \mathrm{ORc}=$ Crude Odds Ratio and $95 \%$ confidence intervals

${ }^{\mathrm{b}} \mathrm{ORa}=$ Odds Ratio adjusted by parity, age and occupation of the mother and $95 \%$ confidence intervals.

* Baseline category 37-41 weeks

Table 4. Evolution of the risk among at term births of being born with 37-39 weeks.

\begin{tabular}{|c|c|c|c|c|}
\cline { 2 - 5 } \multicolumn{1}{c|}{} & \multicolumn{2}{|c|}{ SPANISH } & \multicolumn{2}{c|}{ IMMIGRANTS } \\
\hline & OR $^{*} \mathbf{c}(\mathbf{C I 9 5 \%})^{\mathbf{a}}$ & OR $^{*} \mathbf{a}(\mathbf{C I 9 5 \% )})^{\mathbf{b}}$ & OR $^{*} \mathbf{c}(\mathbf{C I 9 5 \%})^{\mathbf{a}}$ & OR $^{*} \mathbf{( C I 9 5 \% )} \mathbf{b}^{\mathbf{b}}$ \\
\hline $\mathbf{1 9 9 7 - 1 9 9 9}$ & 1 & 1 & 1 & 1 \\
$\mathbf{2 0 0 0 - 2 0 0 2}$ & $1.15(1.14,1.15)$ & $1.14(1.13,1.15)$ & $1.21(1.17,1.25)$ & $1.19(1.15,1.24)$ \\
$\mathbf{2 0 0 3 - 2 0 0 5}$ & $1.33(1.32,1.34)$ & $1.31(1.30,1.32)$ & $1.42(1.38,1.47)$ & $1.39(1.35,1.45)$ \\
$\mathbf{2 0 0 6 - 2 0 0 8}$ & $1.60(1.59,1.61)$ & $1.56(1.54,1.57)$ & $1.89(1.83,1.94)$ & $1.79(1.73,1.85)$ \\
\hline
\end{tabular}

${ }^{\mathrm{a}} \mathrm{ORc}=$ Crude Odds Ratio and $95 \%$ confidence intervals

${ }^{\mathrm{b}} \mathrm{ORa}=$ Odds Ratio adjusted by parity, age and occupation of the mother and $95 \%$ confidence intervals.

* Baseline category 40 weeks 


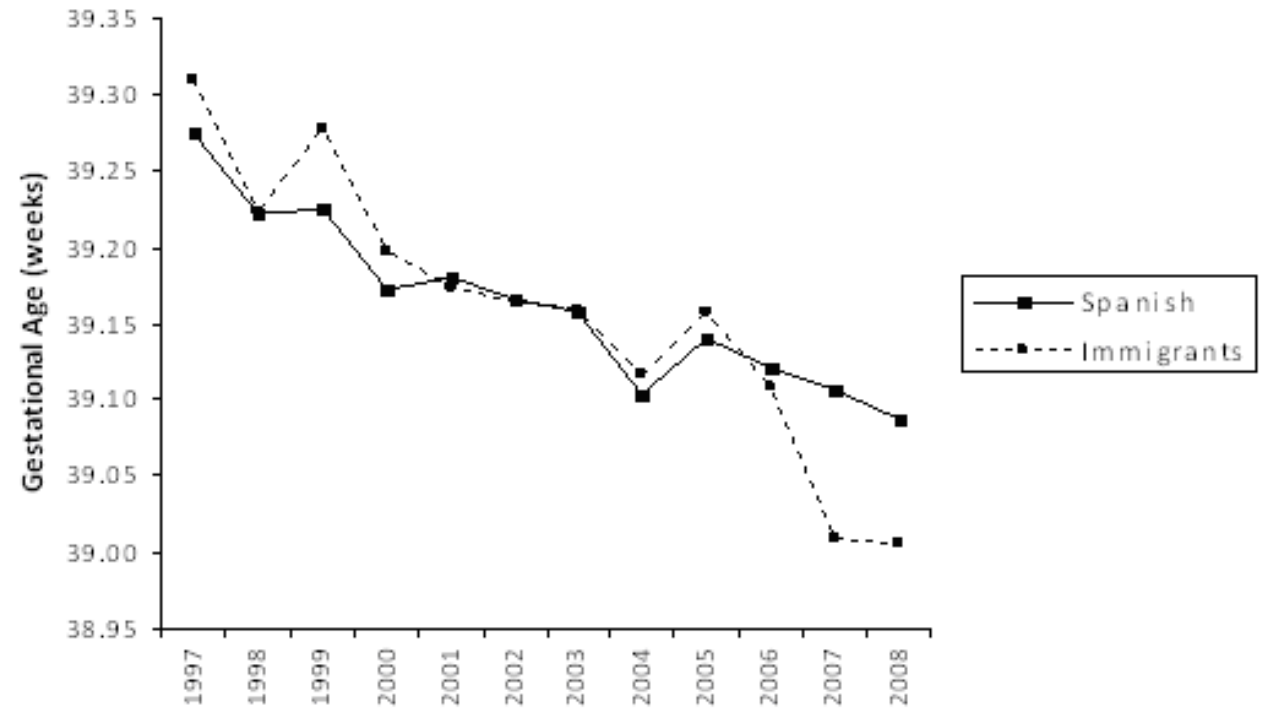

